\title{
Influence of Annealing Process on Wear Resistance of AISI 431 Martensitic Stainless Steel
}

\author{
Animesh Bain ${ }^{1 *}$, B.Ramakrishna Reddy ${ }^{2}$, Prasad Ramchandra Baviskar ${ }^{3}$, Milind M Patil ${ }^{3}$, J.Saranya ${ }^{2}$, \\ P.Geethasree ${ }^{4}$, R.Shruthi ${ }^{4}$, Ram Subbiah $^{5}$ \\ ${ }^{1}$ M.Tech, Design for Manufacturing, Gokaraju Rangaraju Institute of Engineering and Technology, Hyderabad 500090, India \\ ${ }^{2}$ Faculty, Department of Basic sciences and Humanities, Gokaraju Rangaraju Institute of Engineering and Technology, Hyderabad \\ 500090, India \\ ${ }^{3}$ Faculty, Mechanical Engineering, Sandip Institute of Technology and Research Centre, Nashik, Maharashtra 422213, India \\ ${ }^{4}$ UG Students, Mechanical Engineering, Gokaraju Rangaraju Institute of Engineering and Technology, Hyderabad 500090, India \\ ${ }^{5}$ Faculty, Mechanical Engineering, Gokaraju Rangaraju Institute of Engineering and Technology, Hyderabad 500090, India
}

\begin{abstract}
Stainless steel is well known for its good corrosion resistance. It is easily available in the market at low cost. Martensitic stainless steels are hard and brittle in nature, it lacks ductility. Therefore hardness, brittleness, ductility has to be balanced in martensitic stainless steel. Annealing is chosen for this research work to maintain balance between ductility and brittleness. Martensitic stainless steel samples were cut into five small pieces of length $40 \mathrm{~mm}$ and diameter $12 \mathrm{~mm}$ each by using a lathe machine. Annealing process were carried out for three specimens to the temperature $720^{\circ} \mathrm{C}, 820^{\circ} \mathrm{C}, 920^{\circ} \mathrm{C}$ and were named as AN1, AN2, AN3 respectively. One sample is kept aside as untreated for comparison purpose. A wear test was performed on all specimens using a pin-on-disc wear tester to evaluate the material's wear resistance. The results of all samples were compared using a scanning electron microscope and the best material is chosen for the required application.
\end{abstract}

\section{Introduction}

Steel is an iron-based alloy comprising a carbon concentration of 0.02 percent to 1.7 percent by weight, depending on the grade. Stainless steel is less likely to stain, corrode, or rust than normal steel, but it is not stain-proof. Stainless steel is a group of steels that are primarily used to resist corrosion [1-3]. According to metallurgy, stainless steel is a ferrous alloy has a minimum of $10 \%$ chromium content. It refers to a set of corrosion-resistant steels rather than a single substance. The name "stainless steel" comes from the fact that it does not discolor, corrode, or rust as easily as conventional steel. Stainless steel is used for applications that require both corrosion and heat resistance [4-6]. Stainless steel satisfies all of these criteria while maintaining excellent mechanical characteristics. Stainless steel have 10.5 percent chromium as well as additional alloying substances such as molybdenum, nickel, titanium, aluminum, copper, phosphorus, and selenium [7-10].
In their solidified condition, Martensitic steels are comprised with chromium and carbon composites which are hard in nature [11-13]. They are Ferromagnetic and can be hardened with heat, although they are more resistant to wear than other types of treated steels. After solidification, the mixture of chromium and carbon known as chromium-carbide is altered to assure martensitic structure. Carbides in excess is provided to improve wear resistance [14-17]. The applications generally includes Mechanical design for siphon shafts, valves, springs, locks, turbine edges, roller heading and modern blade sharp edges are some of the most common uses [18-20].

The annealing process requires the material to be above the recrystallization temperature for a given time before cooling. The cooling rate depends on the type of annealed metals. The heating process forces atoms to migrate in the crystal lattice, and the number of dislocations decreases, which leads to a change in ductility and hardness. Upon cooling, the thermally 
treated material recrystallizes [21-23]. The crystal grain size and phase composition depend on the rates of heating and cooling, which, in turn, determine the properties of the material. Annealing softens metals, improves grain structure and makes them more ductile. The cooling method largely depends on the desired properties. For the annealing process to be successful, the cooling period must be done slowly and with great care. This heating and slow cooling alters the microstructure of the metal, which in turn decreases its hardness and increases its ductility [23-25].

Grade 431 stainless steel is a general purpose martensitic stainless steel with a chromium content of $15 \%$ and has excellent corrosion resistance. They're frequently used in applications that demand corrosion resistance, high strength and heat resistance [14-17]. Grade 431 steels have a high scaling resistance at temperatures up to $650^{\circ} \mathrm{C}$. Grade 431 steels can be annealed fully at temperatures ranging from 700 to $900^{\circ} \mathrm{C}$, and then progressively cooled in the furnace before being air-cooled [18-20].

\section{Experimental Procedure}

\subsection{Material Composition}

AISI 431 is a high chromium martensitic stainless steel with good corrosion resistance and high yield strength. Chosen for this research work, the elemental composition of AISI431 are shown in the Table 1.

Table 1. Composition of AISI 431 Stainless Steel

\begin{tabular}{|l|l|}
\hline Metals & Composition (\%) \\
\hline Chromium $(\mathrm{Cr})$ & $15.36 \%$ \\
\hline Nickel $(\mathrm{Ni})$ & $1.72 \%$ \\
\hline Carbon $(\mathrm{C})$ & $0.2 \%$ \\
\hline Manganese $(\mathrm{Mn})$ & $0.51 \%$ \\
\hline Phosphorous $(\mathrm{P})$ & $0.018 \%$ \\
\hline Sulphur $(\mathrm{S})$ & $0.008 \%$ \\
\hline Silicon $(\mathrm{Si})$ & $0.46 \%$ \\
\hline Iron $(\mathrm{Fe})$ & Remaining \% \\
\hline
\end{tabular}

\subsection{Tribological wear test:}

AISI 431 stainless steel was chopped into small cylindrical specimens $40 \mathrm{~mm}$ long and $12 \mathrm{~mm}$ in diameter as shown in the Fig 1 . The specimens were annealed to the temperature of $720^{\circ} \mathrm{C}, 820^{\circ} \mathrm{C}, 920^{\circ} \mathrm{C}$. For the wear test, a disc with dimension of $100 \mathrm{~mm}$ diameter and $10 \mathrm{~mm}$ thick were chosen with the same grade. The sliced samples were checked for burrs and other impurities over the entire surface. The wear test were conducted at a constant speed of $1000 \mathrm{rpm}$, constant load of $10 \mathrm{~N}$, Sliding distance $30 \mathrm{~cm}$, Time of 2 Minutes.

Any surface irregularities or burrs formed during cutting are removed by rubbing them with sandpaper according to various estimates. The surface of the samples must also be protected from contaminating influences such as oil and other impurities. The samples are cleaned in acetone solution before being tested for wear test.

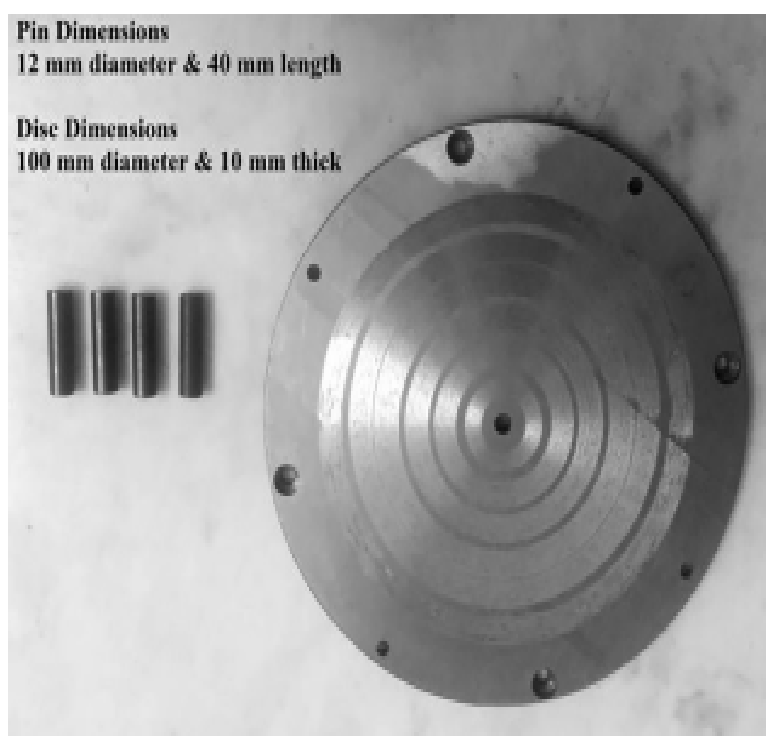

Fig. 1. AISI 431 pin and Disc Samples

The experiments were done on a pin on disc machine and the parameters were adjusted subsequently. The specification of the pin on disc machine are: Company make: Magnum Engineers, Range of load - Up to 220 N, Frictional force - Up to $210 \mathrm{~N}$, Disc diameter $\varnothing 160 \mathrm{~mm}$ (Max), Disc track diameter - 10 to $150 \mathrm{~mm}$, Disc speed - 100 to $2500 \mathrm{rpm}$, Pin Length - 25 to 45 $\mathrm{mm}$, Pin diameter - $3 \mathrm{~mm}$ to $15 \mathrm{~mm}$, Wear measurement (LVDT) - $\pm 3 \mathrm{~mm}$, Pre-set timer range up to $100 \mathrm{Hrs}$. A Pin on disc machine with Selfweight, sensors, pin holder, disc linkage and sliding distance scale were used as shown in Fig 2. The wear loss values were determined by the amount of material detached from the pin. Wear loss were monitored during wear test as shown in the Fig 3. To determine the wear loss, the sample weights were evaluated before and after the test. By monitoring the difference between pre wear test and post wear test weight loss is determined. Microscopic observations were made using Scanning electron microscopic images after conducting wear test for results comparison. 
results.

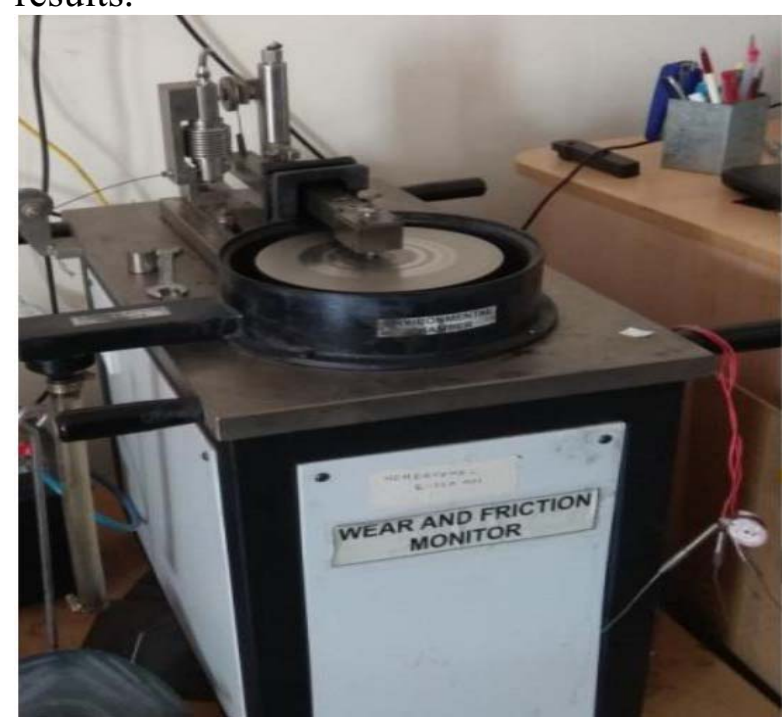

Fig. 2. Pin on Disc Wear Test Machine

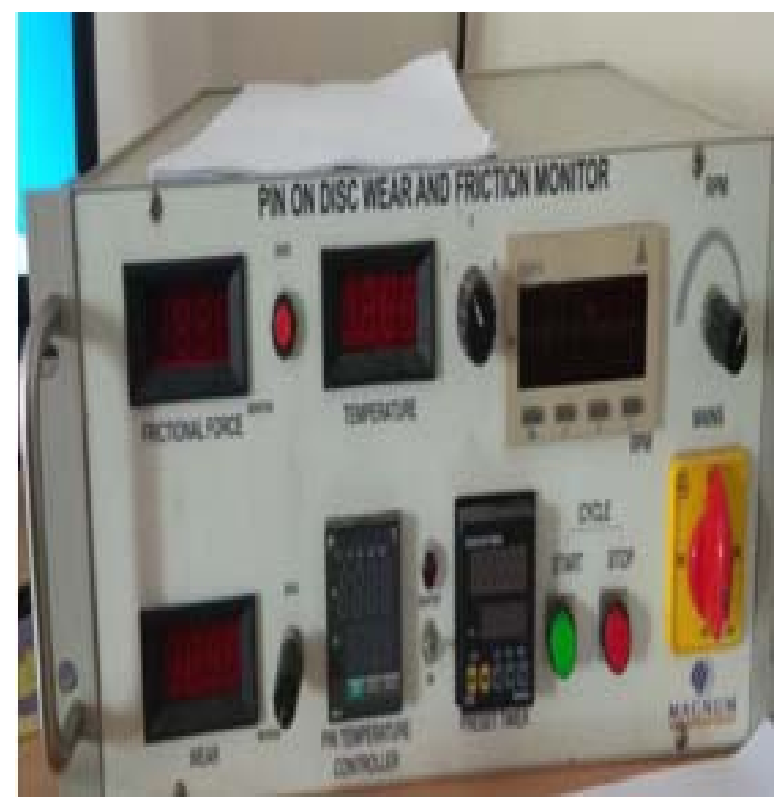

Fig. 3. Pin on Disc Wear Test Monitor

\section{Results and Discussions:}

The hardness of the specimens were measured using Brinell hardness tester against a load of $100 \mathrm{~kg}$ with a time period of 25 seconds. For Untreated 431 stainless steel specimen, it was found to be $380 \mathrm{HB}$, Specimen A1 - $291 \mathrm{HB}$, Specimen A2 - 279 HB, Specimen A3 - 261 HB. For analyzing the surface morphology, microstructure analysis were carried out on AISI 431 steel specimens.

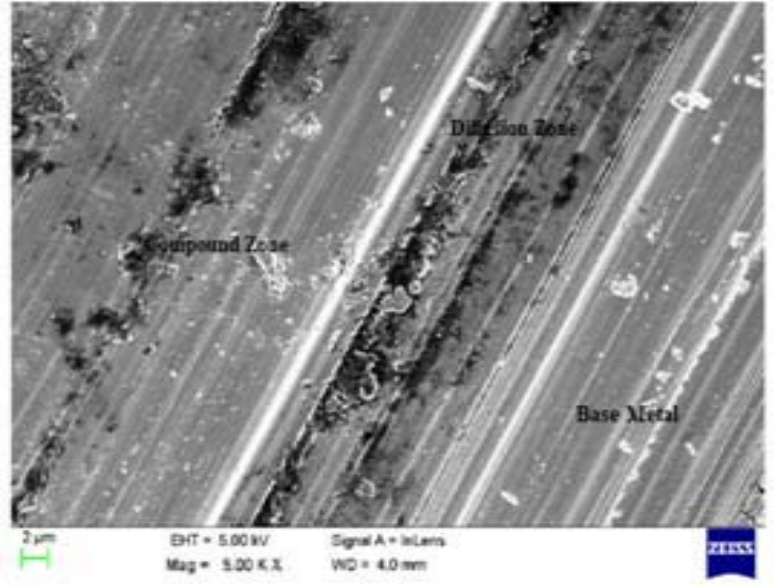

Fig.4. SEM Image of AISI431 Specimen

From the SEM images it was found that for the untreated sample, there was no wear loss as the material is hard and brittle as shown in Fig 4. The hardened microstructure of martensitic stainless steels consists of cementite and residual austenite. While the specimens annealed at temperature of $720^{\circ} \mathrm{C}$, the hardness of the specimen was slightly minimized, promoting ductility. Meanwhile, the brighter phase that appeared on the microstructure slightly transformed to martensite to retained austenite structure stabilizing ductility on the material shown in the Fig 5.

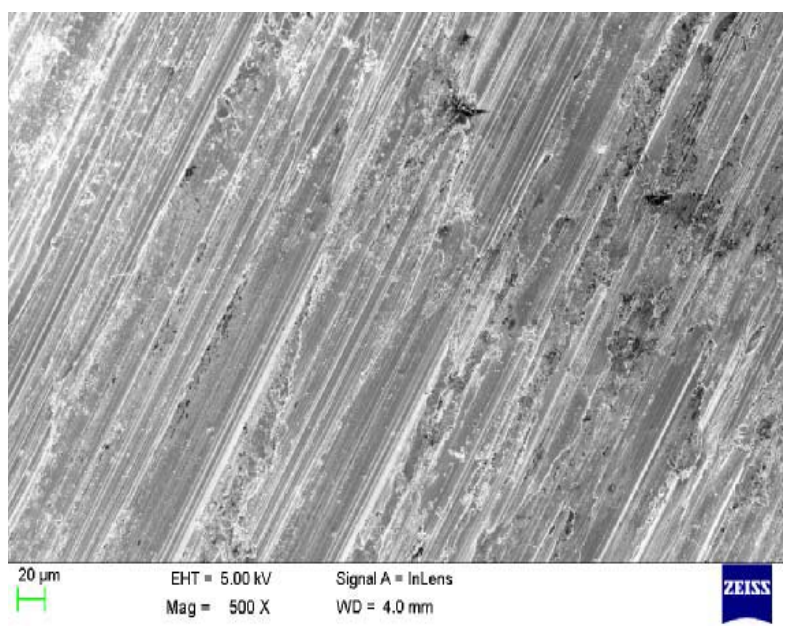

Fig 5: SEM Image of Annealed Specimen at $720^{\circ} \mathrm{C}$ 


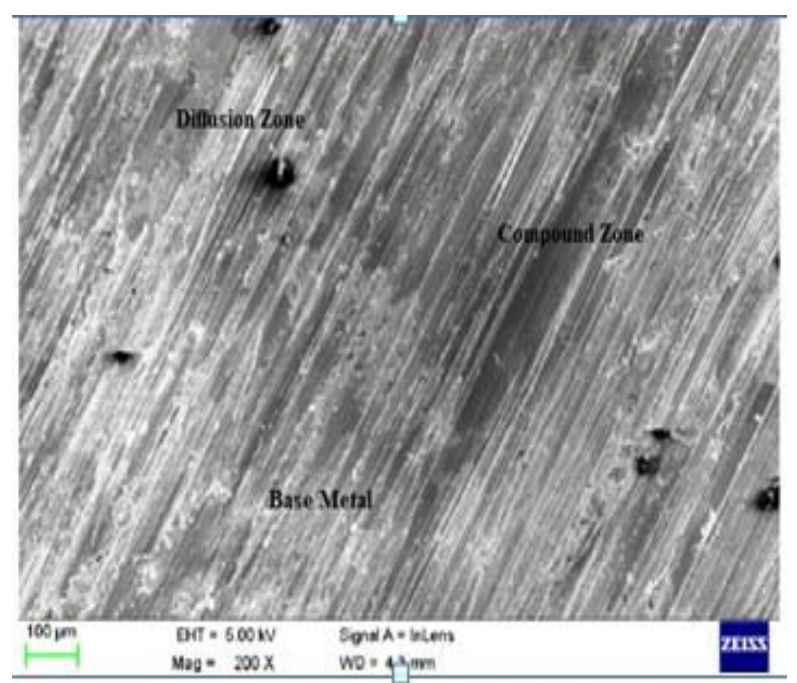

Fig 6: SEM Image of Annealing Specimen at $820^{\circ} \mathrm{C}$

Cracks that have spread on the annealed sample treated at $820^{\circ} \mathrm{C}$, material delamination were also clearly visible. The characteristics of the diffusion zone were analyzed and found to have very small micro-etches were visible in the compound layer. This is due to the external load acting on the specimen as shown in Fig 6. Dense layers on compound layers with the etching pits were visualized. The sparsely formed ferrite along with expanded austenite affects the wear resistance of the annealed specimen, improves the wear resistance.

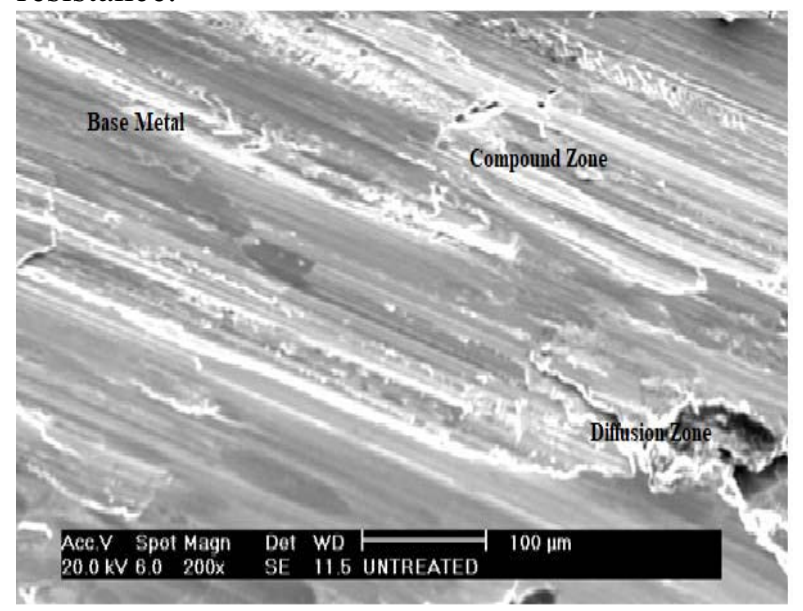

Fig 7: SEM image of Annealed Specimen at $920^{\circ} \mathrm{C}$

The increase in retained austenite in the microstructure after quenching expands the amount of carbon and carbide-forming elements in the solution of the austenite phase, which suppress the martensitic transformation as shown in Fig 7. Some cracks were identified on the specimen and this is due to stabilization of ductility by annealing process on a hard material.

\section{Conclusion}

By annealing process the samples were treated to $720^{\circ} \mathrm{C}, 820^{\circ} \mathrm{C}$, and $920^{\circ} \mathrm{C}$ respectively. As the time of annealing treatment increases the softness of the material increased. Before the heat treatment process, AISI 431 specimen material had high hardness and poor ductility. It was found that wear loss were very low with minimal material loss during the wear test. The property of wear begins to increase to specimen annealed to $920^{\circ} \mathrm{C}$. This was due to formation of unstable carbide occurred during slow cooling process. Finally it was found that the ductility of the specimen increased upon stabilization with hardness decreasing the wear resistance.

\section{References}

1. Y Zhao, B Yu, L Dong, J Xiao, Surf Coat Tech.J.E 210, 90 (2012).

2. M Laleh, F Kargar, M Velashjerdi, Mater Eng Perform.J.E 22, (2013)

3. WP Tong, Z Han, LM Wang, J Lu, K Lu. Surf Coat Technol.J.E 202, 3947 (2008).

4. J. D Majumdar, J. Alphonsa, A. Basu, Wear. J, E 62, 3117 (2008)

5. A.P. Tschiptschina, A. S. Nishikawaa, Luis Bernardo Varelaa, Thin Solid Films.J.E 64496 (2017).

6. T.J. Mesquita, E. Chauveau, M. Mantel, N. Bouvier, D. Koschel, Corros. Sci. J.E 81 (2014).

7. M.Mamatha Gandhi, Animesh Bain, P Rohith, R. Srilatha, Ram Subbiah, Structure and Topography Modifications of Treated AISI 316LN Stainless Steel Surfaces after Friction in Dry Sliding Contact by Case Hardening Process (EDP Sciences, Hyderabad, 2020)

8. K. Ramya Sree, G. K Reddy, K. Aishwarya, E. N Devi, R. Subbiah, New Insights of Wear Behavior Analysis on Low Temperature Treated AISI 253MA Stainless steel Material by Gas Nitriding Process (EDP Sciences, Hyderabad, 2020)

9. A Rohit Sai Krishna, B Vamshi Krishna, D Harshith, T Sashank, Ram Subbiah, Investigation of Mechanical Properties of AISI 316 Stainless Steel by Carbonitriding Process (EDP Sciences, Hyderabad, 2020) 
10. Shivani Koppula, Aakula Rajkumar, Siram Hari Krishna, Reddi Sai Prudhvi, S. Aparna,Ram Subbiah, Improving the Mechanical Properties of AISI 2205 Duplex Stainless Steel by Cryogenic Treatment Process (EDP Sciences, Hyderabad, 2020)

11.Lakshmi Deepak Tadepalli, Ananda Mithra Gosala, Lokesh Kondamuru, Sai Chandra Bairi, A. Anitha Lakshmi, Ram Subbiah, Assessment of Properties on AISI430 Ferritic Stainless Steel by Nitriding process (EDP Sciences, Hyderabad, 2020)

12. Gandla Lakshmi Prasanna, G. Keerthi Reddy, Ram Subbiah, Evaluation of properties of AISI 431 Grade Stainless Steel by Vacuum Annealing Process (EDP Sciences, Hyderabad, 2020)

13. Gandla Lakshmi Prasanna, J Saranya, Ram Subbiah, Assessment of AISI 431Grade Stainless Steel properties by Vacuum Tempering Process (EDP Sciences, Hyderabad, 2020)

14. Manne Vamshi, J. Saranya, Ram Subbiah, Improvement of Characteristics of AISI 310 Grade Stainless Steel Material By Carburizing (EDP Sciences, Hyderabad, 2020)

15. ManneVamshi, AnimeshBain, M.Sreekanth, Ram Subbiah, Wear Characteristics of AISI 310 Grade Stainless Steel Material by Carbonitriding Process (EDP Sciences, Hyderabad, 2020)

16. Ram.Subbiah, Md.Rahel, A.Sravika R.Ambika, A.Srujana, E.Navya, Investigation on Microstructure and Mechanical Properties of P91 Alloy Steel Treated With Normalizing Process - A Review (Materials Today: Proceedings, Hyderabad, 2019)

17. A. Rohit Sai Krishna, B. Vamshi Krishna, T. Sashank, D. Harshith, Ram Subbiah, Influence and assessment of mechanical properties on treated $P 91$ steel with normalizing processes (Materials Today: Proceedings, Hyderabad, 2020)

18. K. Manjith Srinivas, S. Bharath, P. N. V. Krishna Chaitanya, M. Pramod, Ram Subbiah, Improving tribological properties of P91 steels through carburizing process (Materials Today: Proceedings, Hyderabad, 2020)

19. B.Chaitanya kumar, P.Sri Charan, Kanishkar Jayakumar, D.Alankrutha, G.Sindhu, Ram Subbiah, Assessment of wear properties on low temperature molten salt bath nitriding on austenitic stainless steel (Materials Today: Proceedings, Hyderabad, 2020)

20.T.LakshmiDeepak,G.AnandaMithra, K. Lokesh, B. Sai Chandra, Ram Subbiah, Stability of expanded austenite by gas nitriding process on austenitic stainless steel material under low temperature conditions (Materials Today: Proceedings, Hyderabad, 2020)
21. Nirmala Devi, G.Chitra.S, Selvasekarapandian.S Premalatha, M. Monisha, S. Saranya.J, Ionics.J.E 23, 2337 (2017)

22.Patel.S, Rana.R.S, Singh.S.K, Study on mechanical properties of environment friendly Aluminium Ewaste Composite with Fly ash and E-glass fiber (Materials Today: Proceedings, Hyderabad, 2017)

23. Prasad.K.S, Gupta.A.K, Singh.Y, Singh.S.K, Materi Eng and Perform.J.E 25, 5411 (2016)

24. Ganesh.R, Subbiah.R, Chandrasekaran.K, Dry Sliding Wear Behavior of Powder Metallurgy Aluminium Matrix Composite (Materials Today: Proceedings, Hyderabad, 2015)

25. Dhanalaxmi.B, Apparao Naidu.G, Anuradha, K, Adaptive PSO based association rule mining technique for software defect classification using $A N N$ (Procedia Computer Science, Hyderabad, 2015) 